\title{
A PERSONAGEM DA GUERRILHEIRA EM AS MENINAS, DE LYGIA FAGUNDES TELLES, E EM CONVERSACIÓN AL SUR, DE MARTA TRABA
}

\author{
POR \\ CRISTIANE LiRA \\ University of Iowa
}

As coisas têm um rosto distinto quando vivemos o pós-elas.

Adriana Lisboa, Azul-corvo

Neste trabalho, propomos uma leitura da personagem da guerrilheira nas obras As meninas (1973), de Lygia Fagundes Telles, e Conversación al sur (1981), de Marta Traba. ${ }^{1}$ Pioneiros na temática, ambos os romances colocam em cena não apenas protagonistas mulheres, mas também, dentre elas, guerrilheiras. Por meio da leitura proposta, destacamos o espaço que a ficção de Telles e de Traba proporcionou para um primeiro diálogo a respeito das mulheres que resistiram e lutaram contra o regime opressor no Brasil e na Argentina. A partir do exame da composição de Lia (As meninas), além da de Dolores e Victoria (Conversación), argumentamos que a identidade guerrilheira dessas personagens é memorinventada, posto que aparece de modo desviado nas obras. Assim, embora essas mulheres sejam consideradas guerrilheiras, inclusive sendo referidas dessa maneira por outras personagens, essa condição não se concretiza por ações. ${ }^{2}$ Antes, Lia e Dolores, presentes corporalmente nos enredos analisados, podem ser consideradas guerrilheiras sem guerrilhas, isto é, elas são essencialmente capturadas no espaço privado, enredadas em situações de lembranças. A identidade guerrilheira da primeira é construída pela invenção, por meio dos devaneios de Ana Clara. Já em

\footnotetext{
1 Todas as citações do romance As meninas são da edição de 2009. No caso de Conversación al sur (a partir daqui, apenas Conversación), da de 2006.

2 Cunhamos o termo memorinventada para falar da forma como a condição guerrilheira das personagens em questão é representada. Uma vez que essa condição não se concretiza em ações que seriam consideradas de guerrilha em sentido estrito-como sequestros, luta armada ou assaltos a bancos-, ela se recupera em fabulação (pelos delírios de Ana Clara acerca de Lia), em lembranças (por exemplo, no corpo de Dolores, a partir das marcas da tortura) e também no discurso (pelos pensamentos e pelas falas de Irene e de Dolores sobre Victoria, que foi desaparecida).
} 
Dolores, essa característica é acessada a partir das memórias da tortura tatuadas no corpo violentado e débil. Na mesma linha, a identidade guerrilheira de Victoria é aquela que só existe quando lembrada, posto que, por ter sido desaparecida, ela permeia o enredo quando Dolores e Irene se recordam dela. Desse modo, a condição de guerrilheiras das personagens é atravessada pela palavra, seja como fabulação (Ana Clara construindo Lia), seja como lembrança (a memória da tortura no corpo de Dolores e a rememoração de Victoria por Irene e Dolores).

Antes de penetrar o universo das personagens supracitadas, destacamos o potencial de essa comparação contribuir com a fortuna crítica dos dois romances. Embora $A s$ meninas tenha ampla crítica devotada a diversos temas-tais como a análise da memória (Tezza), de aspectos de gênero (Wasserman; Xavier; Leal; Zolin; Oliani 2013), da formação da identidade (Sharpe; Lima e Costa) e do contexto político do período (Dalcastagnè)-, vemos que a posição de Lia como guerrilheira não é desenvolvida como motivo analítico. Mesmo em trabalhos como o de Nara Gonçalves Oliani e Arnaldo Franco Júnior, no qual há uma análise exclusiva de Lia relacionando-a com outras personagens na obra e com o tempo histórico, a condição dela de guerrilheira e representante romanceada da luta armada não é ressaltada. Os autores a leem como expressão de "um segmento idealista e corajoso da mulher brasileira nos anos 60-70" (262); entretanto, sua condição de guerrilheira não é explorada. Logo, essa particularidade da personagem é esquecida.

A mesma omissão sobre a peculiaridade da condição de guerrilheiras de Dolores e de Victoria pode ser observada nas análises do romance Conversación. Ainda que exista extensa e variada fortuna crítica em torno deste (Kantaris 1989 e 1992; Schlau; Perilli; Kaplan; Olivera-Williams; Pietrak 2012 e 2013), a referência à condição de participantes da luta armada é recuperada apenas brevemente em Judith Filc, que em seu artigo nomeia Dolores como "ex-guerrilheira", e em Anne Wesserling, que descreve as personagens como "mujeres involucradas en la guerrilla durante las dictaduras de Argentina y Uruguay" (46). Por um lado, esse levantamento aponta que o potencial de análise dessas personagens como guerrilheiras é terreno que ainda precisa ser explorado. Ao mesmo tempo, revela um questionamento: por que a crítica tem colocado em segundo plano a condição guerrilheira delas? As observações a seguir possibilitarão algumas direções para pensar essa questão.

\section{As personagens Lia e Dolores: dí́logos}

$\mathrm{O}$ início do romance As meninas marca o primeiro contato do leitor com a mente da personagem Lorena. O pensamento que abre a narrativa é a respeito da paixão quase platônica dela por Marcus Nemesius (na maior parte do romance nomeado apenas como M. N.), para depois chegar, por meio de um comentário irônico tecido sobre a

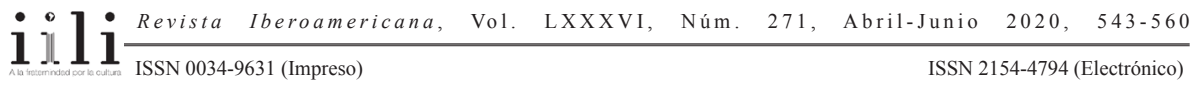


escrita de Lia, à primeira descrição desta como escritora. Numa das primeiras cenas do romance Conversación, logo depois de Irene receber Dolores em casa, ela decide preparar um café como pretexto para se recompor da chegada da visita inesperada. No tempo em que prepara a bebida e a outra a aguarda, Irene relembra o nome da moça que está na sala, Dolores, lembrando-se também que a jovem havia publicado um livro que ela recebeu, mas não deu muita atenção, "siempre pasa eso con la maldita poesía". E adiciona: "Y a quién se le ocurre escribir poesía después de todo" (9), que, embora tenha um tom de pergunta, pela ausência de pontuação também carrega uma marca afirmativa, como se Irene fizesse uma declaração para demonstrar o absurdo de se pensar na estética, no belo, quando tantas coisas horríveis, comportadas pelo vocábulo todo, aconteceram. A pergunta-declaração de Irene nos remete a Theodor Adorno e suas considerações a respeito da palavra e a vivência da experiência: "É bem provável que tenha sido falso afirmar que depois de Auschwitz não é possível escrever nenhum poema", aludindo a uma afirmação própria, porém acrescentando que "não é falsa a questão menos cultural de saber se ainda é possível viver depois de Auschwitz" (301).

Além do fato de que em ambas as obras a primeira identidade associada às mulheres guerrilheiras seja a de escritora, destaca-se também um caráter falível da literatura delas. No caso de Lia, este se relacionaria ao distanciamento entre ações e escrita. Lorena menciona que Lia "fica sublime quando escreve" (13), o que sugere que o ato da escrita adiciona a ela um traço de personalidade que não lhe é comum. Quando reflete sobre a própria escrita, Lia tanto a considera inútil quanto algo que precisa ser destruído. Em um determinado momento da narrativa, Lorena simula que está entrevistando a amiga e, ao perguntar sobre o livro que esta supostamente estaria escrevendo, recebe a resposta de que tudo fora rasgado, acrescentando que "o mar de livros inúteis já transbordou. Ora, ficção. Quem é que está se importando com isso" (29). Nesse trecho, ainda que não apontado diretamente, surge o problema do lugar da ficção em um mundo caótico, no qual a realidade não faz sentido, referência que se conecta diretamente às considerações de Adorno que comentamos anteriormente em relação à fala de Irene em Conversación. De maneira implícita, Lia diz que a literatura precisa ter uma proposta de engajamento. O oposto disso, no entanto, estaria ligado à essência da arte: não há uma utilidade específica para a arte, ela é um fim em si mesma. Daí a falência da literatura de Lia, que não consegue escrever por engajamento: a escrita dela é produzida por ser tocada pelo sublime.

Dolores, em Conversación, reflete sobre dois momentos da própria escrita. O primeiro volta-se a quando escrevia "cosas raras, cosas inútiles que nadie entendía" (56), conjeturando sobre o período no qual entrou para a organização guerrilheira amparada pelo seu companheiro, Enrique, o único que compreendia os seus escritos. O destaque para a "inutilidade" da literatura é, como as observações sobre a escrita de Lia, arrolado ao fato de que não havia espaço para a criação artística, para a invenção,

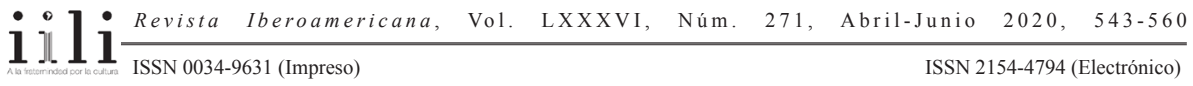


enquanto houvesse uma luta empreendida no cotidiano. Contudo, essa primeira noção de inutilidade é borrada depois do sofrimento, como a própria Dolores explica: “Antes escribía por placer, por vanidad, ¡qué se yo! Ahora porque es mi medio de defensa. Es curioso, pero la poesía me defiende de la vida y me defiende de la muerte. ¿Podés entender eso? Porque las dos cosas son una amenaza para mí. Escribir me tranquiliza, me parece que las dejo atrás, que tomo ventaja" (56). O ato de escrever, portanto, é ressignificado para Dolores depois da violência sofrida, tornando-se um refúgio para a realidade da vida e da morte, transformando-se em um espaço protetor e de resistência.

$\mathrm{O}$ fato de as obras desenharem essas figuras não apenas como escritoras, mas também como questionadoras da utilidade da arte em situações extremas, parece-nos fundamental para compreender a construção da personagem guerrilheira. $\mathrm{O}$ traço da escrita confere a ambas uma característica de sensibilidade, de almas tocadas pelo sublime e que, aparentemente contraditórias, colocam-se em ação na luta contra o Estado repressivo. Isso parece aludir tanto aos inúmeros intelectuais que se engajaram na luta contra a ditadura militar brasileira e argentina quanto ao próprio papel da literatura, pensando em um aspecto metaficcional em que o romance reflete sobre a própria existência como ferramenta de memória, de luta e de arte. Se o sublime parece dar a elas uma característica mais sensível, desenhando-as de maneira mais aproximada à fragilidade e ao feminino, outras características associadas a cada uma amparam personalidades bastante contraditórias e multifacetadas. Dentre elas, apresenta-se o detalhe, que poderia passar desapercebido, de que tanto Lia quanto Dolores, embora falem de companheiros-Miguel para aquela e Enrique para esta-, são apresentadas como mulheres cuja orientação sexual não parece ser tão rígida, haja vista que as duas são construídas destacando-se que tiveram desejos ou relações lesboafetivas.

Em As meninas, há tanto a identidade lésbica apresentada pela própria Lia quanto a questionada pelas outras personagens. No primeiro caso, tomamos conhecimento dessa construção por meio de uma história do passado que ela compartilha com o companheiro Pedro, após ter sido abertamente questionada por ele sobre o assunto, quando então conta sobre o romance que viveu com outra garota na juventude, descrevendo a relação com delicadeza: "Foi um amor profundo e triste" (130). Quanto ao segundo, o questionamento sobre a personagem ser ou não lésbica aparece em diversos momentos do romance. Entretanto, o momento crucial ocorre quando Lorena menciona que a própria mãe já havia perguntado diversas vezes se Lia era lésbica, ao que esta responde: "A situação fica mais preta porque agora não posso exibir Miguel, ô, como as pessoas se impressionam com o sexo do próximo" (211). O trecho é importante porque apresenta em si ideias discordantes. A primeira é a impossibilidade de exibir Miguel, como se tê-lo ao lado garantisse a heterossexualidade. A segunda é o tom displicente de Lia para dizer que as pessoas deveriam se preocupar com a própria vida e não com a dos outros. Entretanto, se ela seguisse mesmo a própria cartilha não sentiria frustração por não

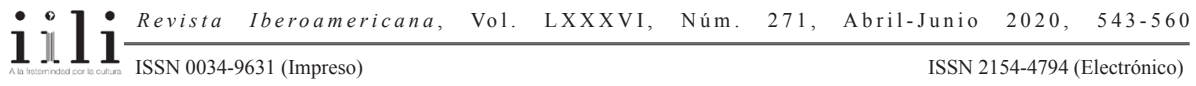


poder exibir o namorado. Desse modo, fica o questionamento: seria Miguel realmente alvo do amor e do desejo de Lia ou seriam eles, como casal, mais um resultado da formação de pares em decorrência da vida militante? Por que o romance acrescenta uma sexualidade ambígua na construção de Lia?

Ao analisar a mesma questão nos traços de Dolores, vemos que, em consequência da própria maneira pela qual a narrativa é construída, o primeiro acesso que temos à sexualidade dela parte de uma observação de Irene transcorrida pela voz de outros: "Aseguraban que era buena escritora, la mejor. Sin duda lesbiana" (20). Parece-nos relevante que essas duas características-ser escritora e lésbica-apareçam juntas porque se sugere que, além de uma simples gradação-isto é, à identidade de escritora soma-se a de lésbica-, o fato de ser mulher e escritora pressupõe que ela seja também lésbica. Essa questão leva-nos a pensar no quanto Traba não desejava discutir, por meio de Dolores, a própria noção de que uma escritura feita por mulheres é sempre permeada pelo estrangeirismo, pelo não pertencimento, tanto quanto a condição de bissexualidade assumida por Dolores, haja vista como ela admite sua fascinação por Irene: "Cada vez que pienso la pasión que sentí al conocer (Irene), me sube la misma oleada de calor a la cara. ¿Qué tipo de pasión?” (135). Segundo Dolores, Enrique seria a pessoa que poderia ajudá-la a descobrir que tipo de paixão, mas não foi possível que eles tivessem tempo para falar sobre isso. Observa-se ainda que, embora ela use paixão para falar de Irene, quando menciona Enrique o destaque é para a relação de carinho e amizade entre os dois.

As relações amorosas de Lia e de Dolores nas obras em questão são construídas de modo muito similar porque o sentimento amoroso, seja ele demonstrado por meio do desejo ou do carinho, é associado à própria relação (Lia) ou ao desejo de uma relação lesboafetiva (Dolores). Por outro lado, ambas estão ou estiveram envolvidas em um relacionamento heterossexual, que parece ter resultado do envolvimento na guerrilha ou acontecido em concomitância com esta. Em Conversación, ao comentar sobre a formação de casais na guerrilha, Dolores aponta que "lo que pasa es que las vidas nuestras, en sí mismas, tienen poca importancia [...] Enrique y yo estábamos juntos, pero a lo mejor yo hubiera podido juntarme igual con Juan; y Enrique con la Flaquita, por ejemplo" (67). Assim, a formação de casais estaria associada a uma conveniência da luta, à afinidade ideológica, e não ao sentimento. Talvez daí a ausência da menção de um possível casal formado por Dolores e Flaquita, o que também pode sugerir que os movimentos organizados contra a ditadura não necessariamente aceitavam a formação de casais do mesmo sexo. ${ }^{3}$

3 A respeito da relação entre ditadura e homossexualidade ver os trabalhos de Guilherme Rodrigues Passamani, "Homossexualidades e ditaduras militares: Os casos de Brasil e Argentina" (2010) e Ditadura e homossexualidades: Repressão, resistência e a busca da verdade (2014) organizado por James N. Green e Renan Quinalha.

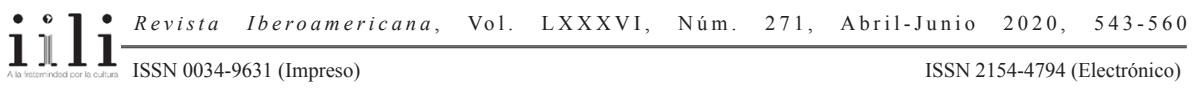


O fato de tanto Lia quanto Dolores terem uma sexualidade ambígua parece-nos importante para compreender a personagem guerrilheira, pois nos leva a questionar a própria construção da identidade feminina da época. Seriam as duas descritas como lésbicas justamente porque são guerrilheiras? Ou a condição guerrilheira somente seria possível porque elas são personagens mais complexas também no aspecto sexual? ${ }^{4}$ Para além de responder a essas perguntas, a relevância recai precisamente no destaque do aspecto ambíguo, multifacetado, pelo qual elas vão sendo constituídas nas obras. Isso significa dizer que a personagem guerrilheira é construída de modo complexo, de maneira a enfatizar uma constituição em múltiplas camadas, rejeitando um modo único de leitura. Em suma, à identidade guerrilheira somam-se descrições que fazem com que as personagens desviem um pouco de discursos engessados de gênero. No entanto, o próprio enfrentamento com a ditadura as coloca em um impasse, uma vez que elas parecem se envolver amorosamente com homens porque essa era a aparente norma das organizações das quais participavam. Por sua vez, o desejo lesboafetivo, embora presente, não se concretiza (Dolores) ou reside em uma relação do passado (Lia). Logo, a condição de guerrilheiras parece empurrá-las para um universo normatizado de gênero.

Para encerrar essa aproximação entre as personagens Lia e Dolores, vale ressaltar que ambas são personagens construídas como guerrilheiras em diferentes graus, mas estão confinadas no espaço fechado de casa. Desse modo, como dissemos, elas poderiam ser consideradas guerrilheiras sem guerrilha. No caso específico de Dolores, ela simboliza um período pós-guerrilha, no qual tudo já passou, "somos los perdedores" (132), e as marcas dessa perda se eternizam em seu corpo disfuncional, ilustradas na quantidade de vezes que ela precisa ir ao banheiro (16), por causa de uma quase incontinência resultante da tortura. A casa, portanto, é um refúgio, o local que parece seguro, mas que, ao final da obra, vai se revelar violável. No caso de Lia, trata-se do espaço onde a guerrilha feita de palavras é pensada e articulada, mas não chega a ocorrer. Pelo contrário, a casa a resguarda para que, sem ação, tenha pensamentos considerados pequeno-burgueses, como quando ela comenta que "queria morrer" (Telles 19) ao saber da prisão de Miguel ou também quando ela não se sente resistente o suficiente para continuar a luta sem ele: "É duro demais cumprir a rotina, queria ser presa" (19). Ressaltamos, porém, que há poucos momentos em que Lia está fora de casa-casa esta na maior parte recuperada, como o quarto de Lorena. Nessas circunstâncias, em que se destaca sobretudo o espaço do aparelho subversivo, a personagem adquire mais força ideológica-por exemplo, quando inicia sexualmente o companheiro Pedro-. No caso

\footnotetext{
4 Tanto Lia quanto Dolores são personagens que não têm muitos atrativos físicos ou que se vestem como homens. Lia, quando descreve o início de seu relacionamento lesboafetivo, comenta: "A gente estudava junto e, como nos achávamos feias, inventamos namorados" (Telles 129). Já Dolores é descrita por Irene como esforçando-se muito "en parecer un muchacho [...] [con] ese saco marinero con los bolsillos deformados de meter libros y cuadernos" (Traba 20).
}

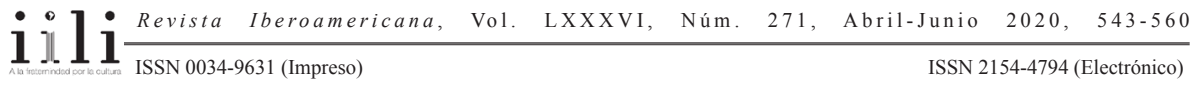


de Dolores, também há uma navegação semelhante, se considerarmos que ela somente revela a sua relação com Victoria no trecho em que está em trânsito entre a casa de Irene e a de seus pais. Nesse sentido, elas são personagens guerrilheiras capturadas sem muito movimento na maior parte das respectivas narrativas. No entanto, quando fora do espaço da casa, o poder de ação delas é aguçado. Isso parece sugerir que o feminino, confinado ao espaço privado, ganha nova dimensão quando liberto pelo mundo, seja pelo pensamento que vira palavra (Dolores), seja pela tomada de decisão consciente de domínio do próprio corpo (Lia).

A comparação feita aqui entre Lia e Dolores aponta traços comuns na constituição das personagens e leva-nos a outras perguntas a respeito da representação da mulher guerrilheira em sentido mais global. Por que Telles e Traba valem-se de perfis tão semelhantes para compor a personagem guerrilheira? Aquestão da escrita seria intrínseca à condição guerrilheira de algum modo ou estaria relacionada ao universo feminino abarcado nas obras em questão? Em que medida a marca da lesboafetividade associada ao corpo guerrilheiro feminino serve para adicionar mais camadas à identidade dessas mulheres? Por que nos dois romances as ações se dão apenas em um universo de compartilhamento de memórias, borrando-se as ações no tempo da narrativa? Estas questões ressaltam que, em vez de termos acesso a um perfil delimitado de como são as personagens, vamos conhecendo-as de modo a perceber que são uma e muitas, vestindo-se de várias características, às vezes até dissonantes. Tudo isso sugere que a personagem guerrilheira tem uma formação complexa, em versões que não são fixas, podendo, aliás, ser memorinventadas, como veremos a seguir.

\section{A GUERRILHEIRA QUE É MEMORINVENÇÃO}

Em As meninas, Lia representa a figura da guerrilheira embora não seja apresentada em ação de guerrilha. Assim, ela tem sua identidade constituída a partir de um acúmulo de narrativas dos outros (em maior grau) e de si mesma (em menor grau). Ainda que não seja apresentada em uma atividade que implique pegar em armas de fogo, ela participa da luta com as armas que tem disponíveis: seja o seu poder de persuasão para solicitar o carro de Lorena para participar de uma ação (17), seja entregando panfletos (118). Esse comportamento de Lia entra em consonância com as observações de Carlos Marighella no Manual do guerrilheiro urbano (1969), em que ele descreve as tarefas a serem desenvolvidas na guerrilha. Em um primeiro momento, a definição de guerrilheiro está associada a atos violentos de guerrilha: "O guerrilheiro urbano é um homem que luta contra uma ditadura militar com armas, utilizando métodos não convencionais" (3). Em outro momento, apontamse os esquemas de pano de fundo que amparam esses atos: "A guerra de guerrilha urbana prepara e coloca ao mesmo nível de responsabilidade e eficiência a homens 
e mulheres que compartilham os mesmos perigos de lutar, buscar suprimentos, servir como mensageiros ou corredores, ou motoristas, ou navegantes, ou pilotos de aviões, obtendo informação secreta, e ajudando com a propaganda ou o trabalho de doutrinação" (60). Logo, a definição de guerrilheiro e guerrilheira não engloba apenas atos específicos de guerrilha, mas pode ser ampliada pela proposta de Marighella.

A partir do exposto, vejamos como o romance As meninas, centrado no pensamento e no cotidiano das três meninas, aponta, por meio do campo semântico, nuances da luta contra a ditadura no Brasil nos anos 1970. Iniciemos com o termo guerrilheira, que aparece na obra em dois momentos, sempre associado às fabulações de Ana Clara. Na primeira incidência do termo, ela produz uma narrativa imaginária para justificar para o noivo o seu atraso, imaginando uma história que gira em torno de um atentado contra Lia: "O caso é que minha amiga Lia foi baleada. A guerrilheira. Guerrilheira é assim, facilitou leva um balaço" (Telles 177). Em um segundo momento, Lia é retomada por Ana Clara enquanto esta conversa com o namorado Max, sempre dentro de uma atmosfera de delírio e fragmentação, e faz considerações sobre a amiga, mencionando que Lião é "guerrilheira e tudo mas o pai também foi um nazista importantíssimo" (178). Nessas ocorrências do termo guerrilheira associado a Lia, vemos que a personagem guerrilheira é construída como fabulação, imaginação, mas imbuída de uma atmosfera dramática, posto que a sua condição é resultado de ter sido baleada e, ao mesmo tempo, de ter uma história familiar contraditória. $\mathrm{O}$ modo como Ana Clara julga Lia representa a forma pela qual uma parte da população brasileira compreendia o que era a luta revolucionária. Esse grupo via os envolvidos com a luta e sobretudo os compreendidos como guerrilheiros e guerrilheiras com uma nuance de mistério e incompreensão, como seres ambíguos, habitando um espaço do meio entre heróis e vilões. Eram um símbolo ficcional e dramático, capturado em uma narrativa imaginada, como se o ser guerrilheiro ou guerrilheira estivesse relacionado ao terreno da fábula, da ficção.

No mesmo campo semântico, ainda por meio do pensamento de Ana Clara, que permanece fabulando uma história para explicar ao noivo o seu atraso, a personagem faz outras considerações sobre Lia, desta vez evocando o termo guerrilha: "E Lião ainda com suas teorias de superioridade da mulher [...] Uma cólica e já avacalha tudo. Se não é cólica é o filho dependurado no peito. Pronto. Mas que guerrilha pode sair disso? Mulher tem que ser assim mesmo. Se embonecar. Vestir coisas lindas" (179). Nesse trecho captura-se um desdobramento da linha de pensamento supracitada que associa à figura imaginativa da guerrilheira um caráter que borra essa condição em decorrência de ser mulher, manchando também essa segunda característica. Nesse sentido, à figura inventada da guerrilheira estaria associada certa fragilidade da biologia do corpo feminino, ressaltada através do que a distingue do masculino; no caso, a cólica da menstruação e a maternidade.

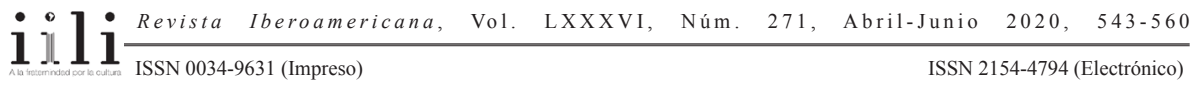


Enquanto a visão que Ana Clara tem de Lia é permeada pela névoa do delírio ocasionado pelas drogas, o modo como Lorena vê Lia-e, por extensão, a revolução-está entre o gracioso e o irônico: "[V]ejo Lião uma mãe gordíssima e felicíssima, sorrindo meio irônica para as passadas guerrilhas, juvenilidades, meu senhor, juvenilidades" (65). E ainda: "Bom tempo para fazer amor mas não revolução que calor muito forte em subdesenvolvido, amolece" (106). Essas e outras passagens do romance soam como se um adulto estivesse observando uma criança, ao mesmo tempo que são de uma amiga emitindo um julgamento da outra. Além dessas passagens, há outros momentos nos quais o olhar julgador de Lorena é destacado. Em um diálogo entre as duas, por exemplo, Lorena pergunta para Lia o que ela fazia nas horas vagas do trabalho com a guerrilha, ao que a amiga responde que não havia momentos livres, que sempre havia algo para fazer: "Oriento um grupo de estudos e traduzo livros. Isso quando não aparece uma missão mais importante" (118). Na sequência, a voz narrativa em terceira pessoa acrescenta, a respeito de Lia: "Insinuou amarrando os cordões das alpargatas". O desfecho da descrição das atividades de guerrilha com o amarrar do calçado simples, acompanhado do verbo insinuar, é ilustrativo dos julgamentos de Lorena. Assim, revela-se o desprezo pelas atividades de Lia, destacando o ato de dar o laço no calçado, ação que parece assemelhá-la a uma criança, infantilizando-a. Logo, Lorena pode ser lida como representante de outra parte da população, que enxerga os revolucionários como pessoas bobas, inconsequentes, infantis. Quando vista pelo olhar dessa personagem, a mulher guerrilheira não é mais fábula-ficção, mas sim a jovem inconsequente recém-saída da infância, que aprendeu ainda há pouco a dar o laço no próprio sapato. Ela é fruto da paixão inconsequente dos jovens, grávida de sonhos e guerrilhas-"juvenilidades, meu senhor, juvenilidades" (65).

$\mathrm{O}$ terceiro modo de memorinventar a guerrilheira e a guerrilha é o interior, ilustrado pelos olhares de Lia para si mesma, como mostra o trecho no qual ela pede a Lorena que pergunte "a mãezinha" desta se ela tinha roupas que gostaria de doar. Lorena responde positivamente, acrescentando que as roupas poderiam ser utilizadas até para que os revolucionários fizessem fardas. Lia, então, acrescenta à observação de Lorena, "[d]e revolucionários sem revolução?" (169). Este trecho apresenta uma visão distópica de seu papel, porque questiona a existência de revolucionários quando já não há revolução. De certo modo, Lia se transforma em um espelho de Lorena, haja vista que essa observação não parece ser dela mesma, embora seja ela quem a emita, mas de Lorena. Lia, portanto, apresenta-se duvidosa dos rumos da revolução.

Somemos ao exame da representação da personagem guerrilheira em As meninas o modo pelo qual a fortuna crítica do romance recupera a condição guerrilheira de Lia e veremos que em muitos trabalhos isso é modalizado por outros termos: "militante de esquerda"(Cavalcante 86), "ativista política de esquerda"(Oliani e Franco Júnior, "Entre o universo" 67), "Lia que acredita na militância política, num ideal revolucionário" 
(Silva 55), "Lia é militante de esquerda e escritora" (Zolin 107). Assim, explicita-se a negação do termo guerrilheira, ainda que este seja utilizado no romance. Quando outros vocábulos associados semanticamente à guerrilha são recuperados nas análises, Lia aparece ligada a eles, mas sua identidade guerrilheira não é retomada. Oliani (“As meninas"), por exemplo, menciona que "Lia fazia parte [de um grupo] que lutava contra o autoritarismo da ditadura, inclusive com o planejamento de uma guerrilha contra os representantes do Governo militar" (107). Neste trecho, destaca-se o distanciamento de Lia das ações (ela é apenas parte de um grupo) e evidencia-se o abismo entre o planejar e o concretizar. Já Tânia Maria de Araújo Lima e Alexsandro Lino da Costa descrevem Lia como "quase uma guerrilheira urbana, pois muito engajada nos planos de movimentos pró-libertação nacional e opositora da repressão política" (ênfase nossa). ${ }^{5}$ A utilização do advérbio que grifamos acrescenta uma imprecisão; afinal, que características a fazem ser uma quase guerrilheira e não simplesmente uma guerrilheira? Por fim, há ainda os trabalhos que a assumem na sua posição guerrilheira (Dalcastagnè; Mello), embora não seja exatamente este o motivo a ser analisado. A partir do exposto, é possível dizer que a condição guerrilheira de Lia, constantemente posta em pauta na narrativa, é também, de certo modo, apagada ou suavizada pela fortuna crítica do romance.

À guerrilheira-que se anuncia pelos delírios de Ana Clara, infantilizada pela voz de Lorena e apagada ou suavizada pelos estudos críticos do romance-, portanto, soma-se a contraditória visão que Lia tem de si mesma. Parece ser possível então, a partir desse percurso, afirmar que a representação da mulher guerrilheira é feita de versões, pontos de vista e conceitos que precisam ser reapropriados e ressignificados não apenas no contexto da luta contra a ditadura militar, mas também em diálogo com a história das mulheres de um modo mais amplo. Mulheres que em geral são concebidas socialmente como menos inclinadas a cometer violência, aspecto intrínseco à noção básica de ações de guerrilha, mas que assumem esse papel a partir de outras atividades, inclusive como motivo que povoa a criação de uma imagem memorinventada.

A partir das observações proporcionadas pelo encontro com a figura da guerrilheira em As meninas, seguimos para um percurso semelhante em Conversación. Na obra de Telles, a palavra articulada pela voz do outro é o recurso para vislumbrar a construção da personagem da mulher guerrilheira. No romance de Traba, é importante destacar que não há apenas uma figura guerrilheira. Dolores, uma das participantes da conversa, é uma ex-guerrilheira que foi presa e torturada, simbolizando assim o corpo guerrilheiro torturado. Além dela, há também Flaquita, ex-guerrilheira trazida ao texto pelas lembranças de Dolores, mas sem desenvolvimento na obra. Finalmente, há Victoria, que consideramos a mais importante ilustração da condição guerrilheira, por ser mais desenvolvida durante a conversa entre Dolores e Irene, além de ser trazida ao texto

Sem número de página no original. 
também pelo pensamento-monólogo-diálogo-de Dolores durante a viagem de ônibus que esta faz para a casa dos pais.

Desse modo, Victoria permite maior destaque para o corpo guerrilheiro ausente, que só existe quando lembrado. Ela é símbolo da representação da mulher guerrilheira pela memória. Em seu próprio nome reside essa aspiração também, haja vista que a vitória já não é visível, suas possibilidades desapareceram, tanto quanto o corpo da guerrilheira. $\mathrm{O}$ que resta são apenas resquícios, a memória dos projetos e sonhos de vitória. Na mesma direção, a personagem que fica, Dolores, aponta pelo seu nome o que sobrou do projeto: uma dor disseminada, lancinante, mas que vem perpassada pela lembrança da possibilidade de vitória. Betina Kaplan, em suas considerações a respeito de como a memória aparece em Conversación al sur, explica que "la memoria representa una zona de máxima visibilidad y tiene un valor de uso" (64), porque por meio dela recuperamos a figura ausente; a memória tem um valor de reconstituição.

A primeira vez em que Victoria é trazida à narrativa é quando Dolores dá-se conta de que Irene havia ido à Argentina no pior momento do país para ajudar Elena, amiga desta. Depois disso, Dolores menciona que "seguro ni sabes que trabajé en el grupo de Victoria. Ya hablaremos de eso" (60). A conversa prossegue sobre o tema anterior até que Irene traz à narração a experiência de ter estado na Argentina "no pior momento" e "nunca [ter visto] una ciudad más impecablemente triste" (66). Esses dados são importantes porque situam a experiência guerrilheira de Victoria em Buenos Aires, além de apontarem um olhar de alguém de dentro-Irene era argentina-, mas que via a cidade a partir de uma nova experiência, relacionada aos reflexos do autoritarismo. Ainda a partir da fala de Irene, outra experiência de ter estado na Argentina, antes de tudo, é trazida à narrativa. Trata-se do reencontro entre ela e a amiga Elena desde a última vez em que haviam se visto em Paris, uma história que, embora preservada por troca de cartas, "se interrumpió por veinte años, casi" (70). Irene comenta que viu Victoria no reencontro, e a beleza da jovem a deixou sem fala (71). A memória desse encontro é forte, e ela conta para Dolores que "cuando llegó la hora de irme me dieron ganas de salir retrocediendo de espaldas, para no perder la visión de lo que era la felicidad" (72). Ao terminar de contar essa memória e a da saída da casa de Elena, repleta da visão da felicidade, no presente da narração há o soar de uma campainha que interrompe o relato e gera pânico em Dolores. Essa relação de simultaneidade entre a memória passada-associada à recuperação da guerrilheira Victoria ainda na sua fase estudantil-e o momento presente interrompido pelo soar da campainha parece sugerir que o simples ato de recordar, desempenhado por Dolores e Irene, pode ser considerado subversivo (Schlau) e, portanto, marcado por interrupções do poder autoritário. ${ }^{6}$

${ }^{6}$ Como propõe Stacey Schlau, "Irene's and Dolores's is a collaborative narrative. Separately, each is a narrator in her own write. Together, they exert a textual authority that elaborates a female version of the Spanish American contemporary chronicle. Their double-voiced tale documents many women's

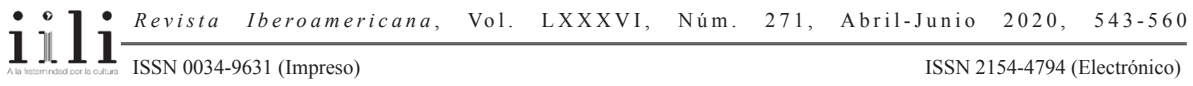


Após o soar da campainha no plano da conversación e algumas reflexões a respeito do medo e de como este se torna intrínseco-"el miedo empieza cuando la cosa te alcanza directamente y te das cuenta de que no, que no estabas a salvo" (74)-, Irene volta a contar sobre Elena, mas dessa vez o foco é a visita depois que Victoria fora desaparecida. Em toda a sequência do encontro entre Elena e Irene, Victoria desaparece também do texto, sendo trazida a este somente por meio de pronomes. Desse modo, sua ausência na casa e na vida cotidiana é materializada na própria sintaxe narrativa. ${ }^{7} \mathrm{O}$ enredo ressalta o desvanecimento de Victoria pela ausência do seu nome ou até mesmo de um pronome do caso reto, valendo-se do uso do pronome oblíquo "la". Isso pode ser lido, por um lado, como uma tentativa de universalizar a condição de Victoria como a experiência de diversas outras militantes guerrilheiras e o processo de apreensão e completo desaparecimento de seus corpos, o apagar de suas existências. Por outro, o fato do nome dela não ser trazido ao texto pode ser simplesmente a marca de que ela já não está, já não existe, já não é. Nesse sentido, ela é universal e inexistente ao mesmo tempo, porque serve de exemplo para os dois extremos na busca pelos desaparecidos: o das famílias que universalizam as experiências individuais em uma coletiva por meio dos reclamos das marchas na Plaza de Mayo e das denúncias às organizações de defesa dos direitos humanos; e o do Estado repressor que fez desaparecer, apagou, eliminou a presença deles.

Embora Victoria seja recuperada tanto por Irene quanto por Dolores, vê-se que a constituição da identidade dela se dá de acordo com cada uma das emissoras. Quando é Irene a emitente, Victoria é a jovem belíssima, filha de sua grande amiga Elena e que está desaparecida. Por outro lado, quando é Dolores quem fala, o acesso que temos a Victoria abrange outros papéis, como a sua identidade feminina, haja vista o comentário sobre o aborto que ela fizera. A construção de Victoria se centra, na maior parte da narrativa, no pensamento de Dolores, o monólogo-diálogo que ela estabelece na travessia até a casa de seus pais. A importância da identidade guerrilheira de Victoria ser trazida à narração por Dolores ganha destaque, porque esta conscientemente utiliza a memória como ferramenta de poder-"'[E]stuvo bien no soltar durante toda la tarde ni una sola palabra de su amistad con Victoria. ¿Para qué decir nada? Mejor que Irene siguiera creyendo que era otra muchacha descarriada más, de buena familia, una tonta que juega a la revolución porque ya no hay muchas cosas que puedan divertirla o excitarla" (99).

experience in the Southern Cone during the 1970's, criticizes complacency, and suggests collective action, even against all odds. It is no wonder therefore, that Conversación al sur ends with what will surely be their disappearance, the government's attempt to silence the two women's conversación"(105, ênfases no original).

7 Verificar o trecho que inicia em "¿No era mejor llorar ahora, así inútilmente, cuando todavía teníamos esperanza de encontrarla?" (Traba 75, ênfase nossa) e termina em "A lo mejor nunca había existido" (76).

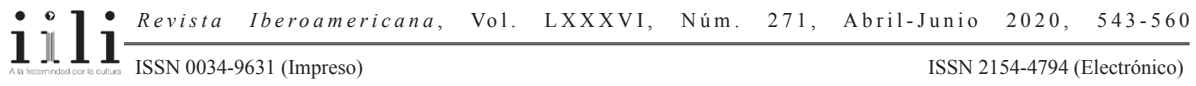


Nesse fragmento, Dolores emite um julgamento cujo alvo parece ser Irene. No entanto, logo depois menciona que "era injusto atribuirle esa idea a Irene. Por la conversación quedó bastante claro que no sólo entendía a Victoria sino que le simpatizaba” (99). Assim, embora tenha partido de um lugar associado a Irene, não se dirige a ela, mas sim a um corpo sócio-histórico generalizado que parece não observar a guerrilha de outra maneira que não como uma espécie de capricho de jovens idealistas. Essa visão é mais uma, que se soma a outras tantas possíveis, pelas quais os guerrilheiros em geral eram compreendidos-eram românticos, bobos, não sabiam o que estavam fazendo-; pensamentos que, em si, retiram o poder de ação deles, infantilizando-os. Pensar sobre essa situação e o modo pelo qual os guerrilheiros são observados, incluindo-se aí ela mesma, ocasiona grande insatisfação e cansaço em Dolores, mas também permite que ela note que a diferença geracional entre ela e Irene não necessariamente significa uma distância de ideologias.

Ainda sobre a identidade guerrilheira memorinventada de Victoria, vale discutila no entorno da terminologia. Diferente de As meninas, em Conversación a questão da guerrilha aparece de maneira mais evidente; não é tão próxima à imaginação, mas sim à memória. Um exemplo disso pode ser visto quando Dolores pensa sobre como era feito o exame para admissão na organização armada, reforçando que este era muito difícil, justamente porque queriam evitar que qualquer "chiquilín más o menos loco resolviera meterse a guerrillero después de una pelea con su papá que no quiso comprarle el automóvil" (105-06). Pensado por uma guerrilheira, Dolores, o modo como os militantes eram selecionados não é utilizado para descrever a condição, mas antes para apresentar algumas das situações às quais a guerrilha estava exposta, como encontrar pessoas que queriam fazer parte do movimento, porém não tinham convicções ideológicas. Nesse sentido, a identidade guerrilheira é apresentada de forma desviada, uma vez que é concebida e representada como uma parcela da sociedade a observava. Trata-se de uma identidade resultante de um desejo de confrontar um grupo, aqui representado pelos pais em uma escala menor e pela sociedade capitalista em uma escala maior.

Outro momento de recuperação da guerrilha pelo aspecto semântico pode ser observado no trecho em que Dolores e Irene conversam sobre o envolvimento da última com a luta. Para Dolores, Irene fala de uma sociedade romântica. Esta, por sua vez, rebate que a luta não é necessariamente entre dois polos, "militares contra lucha armada, pérdida de la guerrilla, liquidación" (167), mas que há um terceiro setor, um grupo que ficou apenas como espectadores da luta. Isso reforça a distância entre o ser e o parecer na maneira como ocorre a representação da identidade guerrilheira. Ao trazer ao texto aqueles que não estão nem de um lado nem do outro da luta, Irene expõe a questão de como os outros-o terceiro setor, como ela nomeia-reagem às representações e também criam outras. A este respeito, ainda em Conversación são recuperadas outras situações 
que apontam como a representação do guerrilheiro era feita a partir da imagem de um corpo monstruoso que precisava ser expurgado e punido. Isso pode ser observado no trecho em que Dolores explica que boa parte da população não se achava parecida com as vítimas da ditadura, não pensava que as filhas da revolução fossem como suas filhas. Essa distinção entre nós e eles era "como una especie de alimaña venenosa, hay que aplastarla sin asco. Éste es el mejor trabajo que han hecho las bestias encaramadas en el poder" (167). Apenas ao apresentá-los como outros, para além da sua condição humana, é que se acrescentava uma nova forma de observar os guerrilheiros: eles se tornavam "esos monstruos de las películas de ficción. O ellos o nosotros. Puestas así las cosas, la gente actúa en legítima defensa" (168).

Esse corpo guerrilheiro memorinventado, distinto, é construído pelo Estado repressor como um corpo marginal, monstruoso, de filmes de ficção científica, de modo a se distanciar dos corpos considerados sadios, convencionais, normais. Esse processo ocorre a partir da propaganda, que, martelada na cabeça do terceiro setor, finalmente cria um aspecto de alteridade a partir do qual as pessoas passam a conceber a identidade guerrilheira como perigosa, de outrem, e que deve, pois, sofrer punições. Estas, por sua vez, são também dignas dos filmes de ficção científica, como Lia menciona em $A s$ meninas, ao comentar sobre um colega, Eurico, que "continua sumido, foi preso assim que desembarcou e até agora ninguém sabe dele. Desapareceu como personagem de ficção científica, quando o homem metálico emite o raio e o tipo se dissolve com revólver e tudo e fica no lugar uma manchinha de gordura" (33). Além do desaparecimento dos opositores, os efeitos do trabalho de terror e propaganda por parte do Estado repressor podem ser capturados na maneira como Cida Costa, que militou na Ação Libertadora Nacional (ALN), narra o episódio da sua prisão no livro Mulheres que foram à luta armada de Luiz Maklouf Carvalho: "Uma mulher começou a gritar: 'Morra, sua terrorista! Morra, sua terrorista!' Foi um impacto. Foi terrível. Você tinha a ilusão de que estava fazendo a coisa numa direção, mas essas mesmas pessoas pelas quais você assumia uma postura, o povo, o teu povo, não estava entendendo" (11).

Às inúmeras representações memorinventadas da personagem guerrilheira, portanto, somam-se também aquelas geradas pelos desencontros de discursos e pontos de vista. Daí a importância de vozes que contribuam a partir de outras perspectivas. É por meio da conversa entre Dolores e Irene que conseguimos ter acesso a várias camadas relacionadas a Victoria. Para Dolores, ela é a guerrilheira que assume o lugar de Andrés na organização com pulso firme. Para Irene, é a jovem de beleza estonteante que, uma vez desaparecida, mergulhou a mãe, Elena, em profunda tristeza. Aliás, Irene sente empatia não apenas porque elas são amigas, mas também porque seu filho e Victoria são como um duplo, haja vista que ele está no Chile durante o início do regime autoritário que derrubou Allende. Sem essas memórias e o verbo que as manifesta, Victoria não poderia estar presente. Para as outras guerrilheiras, de

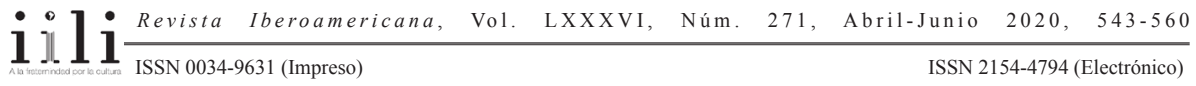


carne e osso, não apenas matéria da ficção, a possibilidade de serem recuperadas por memórias e palavras de sobreviventes, por exemplo, também se faz importante, pois é uma forma de estarem presentes. Forma esta possível porque há alguém que se recorda delas, pessoas que falam a respeito delas e, ainda mais crucial, há ouvintes dispostos a conhecer suas histórias de luta e apagamento pelos repressores. Dessa maneira, ainda que a mulher guerrilheira tenha sido desaparecida, como é de fato o que se passa com a personagem Victoria em Conversación, ela permanece na memória das pessoas que ficam e que compartilham as suas lembranças para reconstituí-la. Assim, a obra aponta um caminho possível para a recuperação das vozes das mulheres guerrilheiras a partir das vozes que compartilharam uma época com elas.

Pela trajetória que percorremos na busca da personagem guerrilheira, seguindo algumas das suas representantes femininas na literatura brasileira e argentina, deparamo-nos com diversas formas pelas quais ela é recuperada e construída. Como pudemos ver, Lia, Dolores e Victoria são personagens cuja condição guerrilheira não é destacada por ações violentas; antes, elas desempenham funções em outras atividades, tais como entregar panfletos e traduzir livros (Lia) ou esconder-se da repressão no plano presente da narrativa enquanto rememora ações feitas por outras (Dolores). Assim, não há necessariamente situações de violência associadas à condição de guerrilheiras. Especialmente no caso de Conversación, essa figura é vista como o corpo que sofre violência. No entanto, mesmo que seus corpos não sejam violentos, elas se valem de outras armas, como a palavra, (re)criando memórias ao trazer para a narrativa guerrilheiras que só existem quando lembradas, quando relato, sobretudo no caso de Conversación. Além disso, as tentativas de leitura da personagem da mulher guerrilheira nas duas obras remetem à ideia de que ela é construída através de olhares nem sempre consonantes e que estes podem ser dos outros para a guerrilheira ou dela para si mesma. Isso permite reforçar a hipótese de que essa figura deve ser observada como um constructo. Tanto Telles quanto Traba tecem suas guerrilheiras como reflexos de um movimento de ecos diferentes a partir de si mesmas e de outras vozes femininas. Da guerrilheira suavizada ou desaparecida pelas leituras críticas ao corpo guerrilheiro que só existe quando lembrado, à guerrilheira que é memorinvenção, a mulher envolvida com a luta contra a ditadura militar no Brasil e na Argentina se torna imagem e vozes. Versões, construções. 


\section{OBRAS CITADAS}

Adorno, Theodor. Dialética negativa. Rio de Janeiro: Jorge Zahar, 2009.

Carvalho, Luiz Maklouf. Mulheres que foram à luta armada. São Paulo: Globo, 1998.

Cavalcante, Ilane Ferreira. "A vida feminina nos anos de chumbo: representações femininas no Brasil nos anos 60 e 70”. Quipus: revista cientifica das escolas de comunicação e artes e educação 1/1 (2011): 83-101.

Chora, Dina Teresa Chainho. "Os romances de Lygia Fagundes Telles: uma tessitura narrativa na senda do humano". Tese de doutorado. Universidade de Lisboa, 2014.

Dalcastagnè, Regina. O espaço da dor: o regime de 64 no romance brasileiro. Brasília: Editora UnB, 1996.

Filc, Judith. "Espacios alterados: la calle y el hogar en tres novelas de la dictadura en el Río de la Plata”. Estudios interdisciplinarios en la América Latina y el Caribe 12/2 (2001).

Green, James N. e Renan Quinalha, orgs. Ditadura e homossexualidades: Repressão, resistência e a busca da verdade. São Carlos: EdUFSCar, 2014.

Kantaris, Elia Geoffrey. "The Politics of Desire: Alienation and Identity in the Work of Marta Traba and Cristina Peri Rossi." Forum for Modern Language Studies 25/3 (1989): 248-64.

"The Silent Zone: Marta Traba." The Modern Language Review 87/1 (1992): 86-101.

Kaplan, Betina. Género y violencia en la narrativa del Cono Sur (1954-2003). Woodbridge: Tamesis, 2007.

Leal, Virgínia Maria Vasconcelos. "Trajetórias femininas e ziguezagueantes: relações de gênero em As meninas de Lygia Fagundes Telles." Estudos de Literatura Brasileira Contemporânea 4 (2000): 7-20.

Lima, Tânia Maria de Araújo e Alexsandro Lino da Costa. "A (des)construção da identidade em As meninas: liquidez, identificação e diferença”. XV Abralic. 8 a 12 de julho de 2013. <http://www.abralic.org.br/anais-artigos/?id=143>. 20 jul. 2015.

Lisboa, Adriana. Azul-corvo. Lisboa: Quetzal, 2012.

Marighella, Carlos. "Manual do guerrilheiro urbano”. Centro de Mídia Independente. $<$ http://brasil.indymedia.org/media/2008/06/422822.pdf>. 20 junho 2015.

Mello, Evelyn Caroline de. "Olhares femininos sobre o Brasil: um estudo sobre $A s$ meninas, de Lygia Fagundes Telles”. Dissertação de mestrado. Universidade Estadual de São Paulo, 2011.

Oliani, Nara Gonçalves. "As representações da mulher em As meninas, de Lygia Fagundes Telles”. Dissertação de mestrado. Universidade Estadual Paulista, 2013. e Arnaldo Franco Júnior. "As meninas: Entre o universo de Lygia Fagundes Telles e o universo das representações femininas”. TriceVersa 4/1 (2010): 65-80. 
“O olhar revolucionário em As meninas". Interdisciplinar 18 (2013): 251-64. Olivera-Williams, María Rosa. "Voces de madres desde la zona del silencio". El arte de crear lo femenino: ficción, género e historia del Cono Sur. Santiago: Editorial Cuarto Propio, 2012.

Passamani, Guilherme Rodrigues. "Homossexualidades e ditaduras militares: Os casos de Brasile Argentina". Fazendo gênero 9-diásporas, diversidades, deslocamentos. 23 a 26 agosto 2010 . $<$ www.fazendogenero.ufsc.br/9/resources/anais/1275391766 arquivo_Passamani.completo.fg9.pdf $>12$ jul. 2015.

Perilli, Carmen. "De susurros como gritos. Conversación al Sur de Marta Traba". Crítica. Revista Latinoamericana de Ensayo (2002). < http://critica.cl/literatura/ de-susurros-como-gritos-conversacion-al-sur-de-marta-traba>. 10 fev. 2013.

Pietrak, Mariola. "En estado de espera: los cuerpos expectantes en la novela de las escritoras del Cono Sur". Del instante a la eternidad: exégesis sobre "la espera" en la escritura de mujeres. José Luis Arráez Llobregat y Amelia Peral Crespo, eds. Alicante: Publicaciones Universidad de Alicante, 2012. 57-76.

"De- y re-construcción del yo femenino en tres autoras hispanoamericanas." Sociocriticism 28 (2013): 167-98.

Schlau, Stacey. “Conversación al sur: Dialogue as History.”Modern Language Studies 22/3 (1992): 98-108.

Sharpe, Peggy. "Fragmented Identities and the Progress of Metamorphosis in Works by Lygia Fagundes Telles.” International Women's Writing: New Landscapes of Identity. Ann Brown, ed. Westport: Greenwood Press, 1995. 78-85.

Silva, Deurilene Sousa. "O indivíduo e as convenções coletivas em As meninas." Dissertação de Mestrado. Universidade Federal do Pará, 2008.

Telles, Lygia Fagundes. As meninas. São Paulo: Companhia das Letras, 2009.

Tezza, Cristovão. Epílogo. As meninas. Lygia Fagundes Telles. São Paulo: Companhia das Letras, 2009. 285-93.

Traba, Marta. Conversación al sur. 1981. México, DF: Siglo XXI Editores, 2006.

Wasserman, Renata R. Mautner. "The Guerrilla in the Bathtub: Telles's As meninas and the Irruption of Politics.” Modern Language Studies 19/1 (1989): 50-65.

Wesserling, Anne M. "Representaciones de violencia y género en cinco narrativas argentinas". Dissertação de mestrado. Universidade da Georgia, 2008.

Xavier, Elódia. Declínio do patriarcado: a família no imaginário feminino. Rio de Janeiro: Rosa dos Tempos, 1998.

Zolin, Lúcia Osana. "A literatura de autoria feminina brasileira no contexto da pósmodernidade". IPOTESI 13/2 (2009): 105-16. 
Palavras-chave: Guerrilheira; Lygia Fagundes Telles; As meninas; Marta Traba; Conversación al Sur

Recebido: $\quad 29$ novembro 2016

Aprovado: $\quad 15$ maio 2017 